1932-February 25, 1933, in the British Isles, is the fifth of a new series that began with vol. 45, published in 1929 ; the introduction to that volume explained the changes introduced in the new series. The week is commonly regarded as the unit of time best suited to the needs of agricultural meteorology, and this report is designed in other respects with the same needs in mind-for example, 'accumulated temperature', which is calculated with $42^{\circ} \mathrm{F}$. as base, above which many forms of plant begin to grow, and statistics of ground frosts, that is, frosts registered by a thermometer set on the grass and freely exposed to the sky as are the upper surfaces of the leaves of the topmost sprays of plants, are among the items included. The tables are set out in such a way that the whole year's succession of weekly data for a single station occupy one page. There are 57 stations, well distributed throughout the British Isles; these are also grouped into twelve so-called 'districts', and the deviations of the various meteorological elements, temperature, rainfall and sunshine, from normal values of these elements for a long period (generally 1881-1915) are averaged so as to give 'district values'. The district values are set out for individual weeks, and these are grouped into the four seasons, for each of which there is an appropriate seasonal mean deviation from normal. The season under review was one of generally deficient sunshine with more than the usual rainfall. The data for the Midlands and for the eastern districts of England and Scotland would be suitable in a study of the agricultural results of a wet spring, as that season was notably wet in those districts.

\section{Investigation of the West Kennet Avenue, Avebury}

Mr. Alexander Keirler has reported briefly in Antiquity of September on the results of an examination of the West Kennet Avenue, which leads from the Great Circle of Avebury to the Stone Circles on Overton Hill, undertaken recently with the view of determining its exact line. The Avenue has never been excavated scientifically; and in the spring of the present year operations were begun in a field about five hundred yards long near the middle of the course. Eight stones were still visible there, as well as one stone, which had never fallen, and one which had been re-erected by Mrs. Cunnington in 1912. The work began in April, and was planned to occupy three seasons. Fallen stones, or stones discovered beneath the surface, are being re-erected in the original holes as the work proceeds. Up to the time of writing, one buried stone, of which the previous existence had been unsuspected, and one fallen stone had been re-erected. In all, eight stone-holes have been discovered on the eastern side of the Avenue and eleven on the western side. One stone hole, despite careful searching, remains undiscovered. It is thought that the stone for which it is sought may not have penetrated the sub-soil, as the soil at the point where this stone most probably stood is unusually deep. Four other buried stones have been found and on three of these are markings which may be inscribed ornament. Post holes for timber uprights of which traces remain may, it is thought, represent a habitation site. The associated pottery is of the type known as Neolithic $B$, that is, Peterborough, which in this region belongs to the secondary occupation of the neighbouring Windmill Hill. Two finds of foreign stone, broken polished axes, are of augite-granophyre from Graig Llwyd. This occurs only at Penmaenmawr, North Wales, and previously only three specimens had been recorded outside Wales, one being from Windmill Hill, and equating with Neolithic $B$ pottery.

\section{Experimental Soil Science}

THE experimental study of the soil is so essential a branch of courses in agriculture, horticulture, botany and biology, that it seems a pity it is rather neglected, especially in the last two subjects, from elementary school courses up to courses in the universities. Most textbooks of botany, for example, devote little space to soil science in spite of the fact that the soil is the sole environment responsible for the physiological, biological and edaphic factors affecting one of the most important organs of the normal plant, namely, the root. We would therefore direct the attention especially of teachers of elementary biology and botany to an article on the experimental study of the soil by Dr. B. A. Keen, assistant director of Rothamsted Experimental Station, in School Nature Study, vol. 29, No. 117, October 1934. The author describes 18 experiments with a running commentary divided into four sections: what is meant by soil; organic matter; mineral matter; and separation of soil constituents. The paper is also published separately as Leaflet 22, copies of which can be obtained at $2 \frac{1}{2} d$. each, or $2 s$. a dozen, from Mr. E. G. Clarke, 7 Stanley Avenue, Wembley, Middlesex.

\section{Gulls Destroy Grasshoppers}

IT is surprisingly seldom that one comes across telling examples of the activity of birds as destroyers of harmful insects. F. Bradshaw records an interesting experience in Canada, on the west side of Last Mountain Lake, east of Liberty, Saskatchewan (Canadian Naturalist, 48, 68, April 1934). On June 18, 1933, he observed there what in the distance appeared to be a cloud of smoke, but on nearer approach turned out to be enormous flocks of the black-headed Franklin's gull. They alighted in column formation and gorged upon an army of grasshoppers. The number of birds present could not be estimated closely, but the column of close-set birds was a mile in extent and sixty birds in width, and two miles to the south-west an even larger cloud of gulls was seen. Estimates suggest that a Franklin's gull might devour 500 grasshoppers daily; the protective value of a flock, which at a very conservative estimate numbered more than a million, is, therefore, of considerable moment.

\section{Giuseppe Peano}

Among the eighteen papers in the Rendiconti del Seminario Mathematico e Fisico di Milano (7, 1933), the longest, and, to the general reader, most interesting, is an account of the scientific work of G. Peano of Turin (1858-1932). His publications, numbering 